\title{
Non-self multivariate contraction mapping principle in Banach spaces
}

\author{
Yanxia Tang ${ }^{a, *}$, Jinyu Guan ${ }^{a}$, Yongchun Xü ${ }^{a}$ Yongfu Su \\ ${ }^{a}$ Department of Mathematics, College of Science, Hebei North University, Zhangjiakou 075000, China. \\ ${ }^{b}$ Department of Mathematics, Tianjin Polytechnic University, Tianjin 300387, China.
}

Communicated by Y. H. Yao

\begin{abstract}
The purpose of this article is to prove the non-self multivariate contraction mapping principle in a Banach space. The main result is the following: let $\mathrm{C}$ be a nonempty closed convex subset of a Banach space $(X,\|\cdot\|)$. Let $\mathrm{T}: \mathrm{C} \rightarrow \mathrm{X}$ be a weakly inward $\mathrm{N}$-variables non-self contraction mapping. Then $\mathrm{T}$ has a unique multivariate fixed point $\mathrm{p} \in \mathrm{C}$. That is, there exists a unique element $p \in C$ such that $T(p, p, \cdots, p)=p$. In order to get the non-self multivariate contraction mapping principle, the inward and weakly inward $\mathrm{N}$-variables non-self mappings are defined. In addition, the meaning of $\mathrm{N}$-variables non-self contraction mapping $\mathrm{T}: \mathrm{C} \rightarrow \mathrm{X}$ is the following:
\end{abstract}

$$
\|T x-T y\| \leqslant h \nabla\left(\left\|x_{1}-y_{1}\right\|,\left\|x_{2}-y_{2}\right\|, \cdots,\left\|x_{N}-y_{N}\right\|\right)
$$

for all $x=\left(x_{1}, x_{2}, \cdots, x_{N}\right), y=\left(y_{1}, y_{2}, \cdots, y_{N}\right) \in C^{N}$, where $h \in(0,1)$ is a constant, and $\nabla$ is an $N$-variables real function satisfying some suitable conditions. The results of this article improve and extend the previous results given in the literature. (C)2017 All rights reserved.

Keywords: Non-self mapping, Caristi's fixed point theorem, contraction mapping principle, multivariate fixed point, inward condition, weakly inward condition, iterative sequence.

2010 MSC: 47H05, 47H10.

\section{Introduction}

Banach contraction mapping principle is one of the important tools (or methods) in nonlinear analysis and other mathematical fields. Weak contractions are generalizations of Banach contraction mappings which have been studied by several authors. In 1968, Browder [4] proved a $\phi$-contraction mapping principle. Subsequently, this result was extended in 1969 by Boyd and Wong [5] by weakening the hypothesis on $\phi$, in the sense that it is sufficient to assume that $\phi$ is right upper semi-continuous. For a comprehensive study of relations between several such contraction type conditions, see [7, 11, 12, 19]. In 1973, Geraghty [7] introduced the Geraghty-contraction and obtained the fixed point theorem. On the other hand, in 2015, $\mathrm{Su}$ and Yao [18] proved a more generalized contraction mapping principle. In particular, the study of the fixed points for weak contractions and generalized contractions was extended to partially ordered metric

\footnotetext{
*Corresponding author

Email addresses: sutang2016@163.com (Yanxia Tang), guanjinyu2010@163.com (Jinyu Guan), hbxuyongchun@163.com (Yongchun Xu), tj suyongfu@163.com (Yongfu Su)

doi:10.22436/jnsa.010.09.13
} 
spaces in [2, 8-10, 15-17]. Among them, some results involve altering distance functions. Such functions were introduced by Khan et al. in [14], where some fixed point theorems are presented. In 2016, Su et al. [17] presented the concept of multivariate fixed point and proved a multivariate fixed point theorem for the $\mathrm{N}$-variables contraction mappings which further generalizes Banach contraction principle.

The following are more relevant content with the subject of this article.

In 1976, Caristi [6] put forward Caristi's fixed point theorem:

Theorem 1.1 ([6, Caristi's fixed point theorem]). Let $\mathrm{X}$ be a complete metric space, $f: X \longrightarrow X$ be a mapping, and $\phi: \mathrm{X} \longrightarrow \mathrm{R}^{+}$be a lower semi-continuous functional. If

$$
\mathrm{d}(x, \mathrm{f}(\mathrm{x})) \leqslant \phi(x)-\phi(\mathrm{f}(\mathrm{x})), \quad \forall x \in X,
$$

where $\mathrm{R}^{+}$is the set of the positive real numbers, then $\mathrm{f}$ has a fixed point.

In 2009, Agarwal et al. [1] proved the following non-self contraction mapping principle by using Caristi's fixed point theorem.

Theorem 1.2 ([1]). Let $\mathrm{C}$ be a nonempty closed convex subset of a Banach space $(\mathrm{X},\|\cdot\|)$. Let $\mathrm{T}: \mathrm{C} \rightarrow \mathrm{X}$ be a weakly inward non-self contraction mapping. Then T has a unique fixed point.

The purpose of this article is to prove the non-self multivariate contraction mapping principle in a Banach space. In order to get the non-self multivariate contraction mapping principle, the inward and weakly inward $\mathrm{N}$-variables non-self mappings are defined. Of course, the meaning of $\mathrm{N}$-variables non-self contraction mapping will be defined. The results of this article improve and extend the previous results given in the literature.

\section{Preliminaries}

Definition 2.1 ([17]). Let $(X, d)$ be a metric space, $T: X^{N} \rightarrow X$ be an $N$-variables mapping. An element $p \in X$ is called a multivariate fixed point if

$$
p=T(p, p, \cdots, p) .
$$

Definition 2.2 ([1]). Let $C$ be a nonempty subset of a Banach space $(X,\|\cdot\|)$. For $x \in C$, the inward set of $x$ relative to $C$ is the set

$$
I_{C}(x)=\{x+t(y-x): y \in C, t \geqslant 0\} .
$$

Definition 2.3 ([1]). Let $C$ be a nonempty subset of a Banach space $(X,\|\cdot\|)$. Let $T: C \rightarrow X$ be a mapping. Then $T$ is said to be

(1) inward mapping if $T x \in \mathrm{I}_{\mathrm{C}}(x)$ for all $x \in \mathrm{C}$,

(2) weakly inward mapping if $\mathrm{T} x \in \overline{\mathrm{I}_{\mathrm{C}}(x)}$ for all $x \in C$,

where $\overline{\mathrm{I}_{C}(x)}$ is the closure of the set $\mathrm{I}_{C}(x)$.

Definition 2.4 ([1]). Let $C$ be a nonempty subset of a Banach space $(X,\|\cdot\|)$. Let $T: C \rightarrow X$ be a non-self mapping. Then $T$ is said to be a non-self contraction mapping, if there exists a constant $0<\mathrm{h}<1$ such that

$$
\|T x-T y\| \leqslant h\|x-y\|, \forall x, y \in C .
$$

In this section we present the following concepts which are useful in our approach. In particular, the following Definition 2.5 is an extension of Definition 2.3.

Definition 2.5. Let $C$ be a nonempty subset of a Banach space $(X,\|\cdot\|)$. Let $T: C^{N} \rightarrow X$ be an $N$-variables mapping. Then $T$ is said to be 
(1) inward mapping if $T x \in I_{C}\left(x_{i}\right)$ for all $x=\left(x_{1}, x_{2}, \cdots, x_{N}\right) \in C^{N}$,

(2) weakly inward mapping if $\mathrm{T} x \in \overline{\mathrm{I}_{\mathrm{C}}\left(\mathrm{x}_{i}\right)}$ for all $x=\left(x_{1}, x_{2}, \cdots, x_{N}\right) \in \mathrm{C}^{\mathrm{N}}$, where $\mathrm{C}^{\mathrm{N}}=\mathrm{C} \times \mathrm{C} \times \cdots \times \mathrm{C}$ is the Cartesian product of the set $\mathrm{C}$.

Definition 2.6. A multiply normed function $\nabla\left(a_{1}, a_{2}, \cdots, a_{N}\right)$ is a continuous $N$ variables non-negative real function with the domain

$$
\left\{\left(a_{1}, a_{2}, \cdots, a_{N}\right) \in R^{N}: a_{i} \geqslant 0, i \in\{1,2,3, \cdots, N\}\right\}
$$

which satisfies the following conditions:

(1) $\nabla\left(a_{1}, a_{2}, \cdots, a_{N}\right)$ is non-decreasing for each variable $a_{i}, i \in\{1,2,3, \ldots, N\}$;

(2) $\nabla\left(a_{1}, a_{2}, \cdots, a_{N}\right) \longrightarrow 0 \Leftrightarrow a_{i} \longrightarrow 0, i \in\{1,2,3, \cdots, N\}$;

(3) $\nabla\left(\lambda a_{1}, \lambda a_{2}, \cdots, \lambda a_{N}\right)=\lambda \nabla\left(a_{1}, a_{2}, \cdots, a_{N}\right), \quad \forall \lambda \geqslant 0$;

(4) $\nabla\left(a_{1}+b_{1}, a_{2}+b_{2}, \cdots, a_{N}+b_{N}\right) \leqslant \nabla\left(a_{1}, a_{2}, \cdots, a_{N}\right)+\nabla\left(b_{1}, b_{2}, \cdots, b_{N}\right)$;

(5) $\nabla(a, a, \cdots, a)=a$

for all $a_{i}, b_{i}, a \in \mathbb{R}, i \in\{1,2,3, \cdots, N\}$, where $\mathbb{R}$ denotes the set of all real numbers.

The following are some basic examples of multiply normed functions:

Example 2.7. $\nabla_{1}\left(a_{1}, a_{2}, \cdots, a_{N}\right)=\frac{1}{N} \sum_{i=1}^{N} a_{i}$.

Example 2.8. $\nabla_{2}\left(a_{1}, a_{2}, \cdots, a_{N}\right)=\sum_{i=1}^{N} \lambda_{i} a_{i}, \lambda_{i} \in(0,1), \sum_{i=1}^{N} \lambda_{i}=1$.

Example 2.9. $\nabla_{3}\left(a_{1}, a_{2}, \cdots, a_{N}\right)=\sqrt{\frac{1}{N} \sum_{i=1}^{N} a_{i}^{2}}$.

It is obvious that $\nabla_{3}$ satisfies conditions (1)-(3) and (5). So we only need to check condition (4). From the definition of the $\nabla_{3}$, we have, by using Minkowski inequality, that

$$
\begin{aligned}
\nabla_{3}\left(a_{1}+b_{1}, a_{2}+b_{2}, \cdots, a_{N}+b_{N}\right) & =\sqrt{\frac{1}{N} \sum_{i=1}^{N}\left\|a_{i}+b_{i}\right\|^{2}} \leqslant \sqrt{\frac{1}{N} \sum_{i=1}^{N}\left(\left\|a_{i}\right\|+\left\|b_{i}\right\|\right)^{2}} \\
& \leqslant \sqrt{\frac{1}{N} \sum_{i=1}^{N}\left\|a_{i}\right\|^{2}+\sqrt{\frac{1}{N} \sum_{i=1}^{N}\left\|b_{i}\right\|^{2}}} \\
& =\nabla_{3}\left(a_{1}, a_{2}, \cdots, a_{N}\right)+\nabla_{3}\left(b_{1}, b_{2}, \cdots, b_{N}\right) .
\end{aligned}
$$

Example 2.10. $\nabla_{4}\left(a_{1}, a_{2}, \cdots, a_{N}\right)=\max \left\{a_{1}, a_{2}, \cdots, a_{N}\right\}$.

\section{Main results}

Lemma 3.1. Let $X$ be a Banach space with the norm $\|\cdot\|$. We consider on the Cartesian product space $X^{\mathrm{N}}=$ $\mathrm{X} \times \mathrm{X} \times \cdots \times \mathrm{X}$ the following functional

$$
\|x\|_{*}=\nabla\left(\left\|x_{1}\right\|,\left\|x_{2}\right\|, \cdots,\left\|x_{N}\right\|\right), \quad \forall x=\left(x_{1}, x_{2}, \cdots, x_{N}\right) \in X^{N},
$$

where $\nabla$ is a multiply normed function. Then $\left(\mathrm{X}^{\mathrm{N}},\|\cdot\|_{*}\right)$ is a Banach space. 
Proof. We need firstly to check the following conditions:

(1) $\|x\|_{*} \geqslant 0$ and $\|x\|_{*}=0 \Leftrightarrow x=0, x \in X^{N}$;

(2) $\|\lambda x\|_{*}=|\lambda|\|x\|_{*}, \forall x \in X^{N}, \lambda \in R$;

(3) $\|x+y\|_{*} \leqslant\|x\|_{*}+\|y\|_{*}, \forall x, y \in X^{N}$.

The conditions (1) and (2) are obvious. Next, we only need to check the condition (3). From the definition of $\|\cdot\|_{*}$, we have that

$$
\begin{aligned}
\|x+y\|_{*} & =\nabla\left(\left\|x_{1}+y_{1}\right\|,\left\|x_{2}+y_{2}\right\|, \cdots,\left\|x_{N}+y_{N}\right\|\right) \\
& \leqslant \nabla\left(\left\|x_{1}\right\|+\left\|y_{1}\right\|,\left\|x_{2}\right\|+\left\|y_{2}\right\|, \cdots,\left\|x_{N}\right\|+\left\|y_{N}\right\|\right) \\
& \leqslant \nabla\left(\left\|x_{1}\right\|,\left\|x_{2}\right\|, \cdots,\left\|x_{N}\right\|\right)+\nabla\left(\left\|y_{1}\right\|,\left\|y_{2}\right\|, \cdots,\left\|y_{N}\right\|\right) \\
& =\|x\|_{*}+\|y\|_{*}
\end{aligned}
$$

for all $x=\left(x_{1}, x_{2}, \cdots, x_{N}\right), x=\left(x_{1}, x_{2}, \cdots, x_{N}\right) \in X^{N}$. We secondly need to prove that $\left(X^{N},\|\cdot\|_{*}\right)$ is complete. Let $\left\{x_{n}\right\}$ be a Cauchy sequence in the linear normed space $\left(X^{N},\|\cdot\|_{*}\right)$, where

$$
x_{n}=\left(x_{n, 1}, x_{n, 2}, \cdots, x_{n, N}\right), n=1,2,3, \cdots .
$$

In this case, we have that

$$
\lim _{n, m \rightarrow \infty}\left\|x_{n}-x_{m}\right\|_{*}=\lim _{n, m \rightarrow \infty} \nabla\left(\left\|x_{n, 1}-x_{m, 1}\right\|,\left\|x_{n, 2}-x_{m, 2}\right\|, \cdots,\left\|x_{n, N}-x_{m, N}\right\|\right)=0,
$$

which implies that

$$
\lim _{n, m \rightarrow \infty}\left\|x_{n, i}-x_{m, i}\right\|=0, \quad \forall i=1,2,3, \cdots, N .
$$

Since $(X,\|\cdot\|)$ is a Banach space, there exist $x_{1}, x_{2}, \cdots, x_{N}$ such that

$$
\lim _{n, m \rightarrow \infty}\left\|x_{n, i}-x_{i}\right\|=0, \quad \forall i=1,2,3, \cdots, N .
$$

Let $x=\left(x_{1}, x_{2}, \cdots, x_{N}\right)$, then, we have

$$
\lim _{n \rightarrow \infty}\left\|x_{n}-x\right\|_{*}=\lim _{n \rightarrow \infty} \nabla\left(\left\|x_{n, 1}-x_{1}\right\|,\left\|x_{n, 2}-x_{2}\right\|, \cdots,\left\|x_{n, N}-x_{N}\right\|\right)=0,
$$

which implies that the sequence $\left\{x_{n}\right\}$ converges, in $\|\cdot\|_{*}$, to $x$. Hence $\left(X^{N},\|\cdot\|_{*}\right)$ is complete. This completes the proof.

In this section, we give the following definition which is an extension of Definition 2.4.

Definition 3.2. Let $C$ be a nonempty subset of a Banach space $(X,\|\cdot\|)$. Let $T: C^{N} \rightarrow X$ be an $N$-variables mapping. Then $T$ is said to be a non-self $\nabla$-contraction mapping, if there exists a constant $0<\mathrm{h}<1$ such that

$$
\|T x-T y\| \leqslant h \nabla\left(\left\|x_{1}-y_{1}\right\|,\left\|x_{2}-y_{2}\right\|, \cdots,\left\|x_{N}-y_{N}\right\|\right)
$$

for all $x=\left(x_{1}, x_{2}, \cdots, x_{N}\right), y=\left(y_{1}, y_{2}, \cdots, y_{N}\right) \in C^{N}$, where $\nabla$ is a given multiply normed function.

Now, we prove the following lemmas which are useful for our main results.

Lemma 3.3. Let $\mathrm{C}$ be a nonempty subset of a Banach space $(\mathrm{X},\|\cdot\|)$. Banach space $\left(\mathrm{X}^{\mathrm{N}},\|\cdot\|_{*}\right)$ is defined by Lemma 3.1. Let $\mathrm{T}: \mathrm{C}^{\mathrm{N}} \rightarrow \mathrm{X}$ be an $\mathrm{N}$-variables non-self $\nabla$-contraction mapping. Let $\mathrm{T}^{*}: \mathrm{C}^{\mathrm{N}} \rightarrow \mathrm{X}^{\mathrm{N}}$ be a mapping defined by

$$
\mathrm{T}^{*}\left(\mathrm{x}_{1}, \mathrm{x}_{2}, \cdots, \mathrm{x}_{\mathrm{N}}\right)=\left(\mathrm{T}\left(\mathrm{x}_{1}, \mathrm{x}_{2}, \cdots, \mathrm{x}_{\mathrm{N}}\right), \mathrm{T}\left(\mathrm{x}_{1}, \mathrm{x}_{2}, \cdots, \mathrm{x}_{\mathrm{N}}\right), \cdots, \mathrm{T}\left(\mathrm{x}_{1}, \mathrm{x}_{2}, \cdots, \mathrm{x}_{\mathrm{N}}\right)\right)
$$

for any $\left(x_{1}, x_{2}, \cdots, x_{N}\right) \in C^{N}$. Then $\mathrm{T}^{*}$ is a non-self contraction mapping in Banach space $\left(\mathrm{X}^{\mathrm{N}},\|\cdot\|_{*}\right)$. 
Proof. From the definition of the norm $\|\cdot\|_{*}$, we have that

$$
\begin{aligned}
\left\|\mathrm{T}^{*}(\mathrm{x})-\mathrm{T}^{*}(\mathrm{y})\right\|_{*} & =\nabla(\|\mathrm{T} x-\mathrm{T} y\|,\|\mathrm{T} x-\mathrm{Ty}\|, \cdots,\|\mathrm{T} x-\mathrm{T} y\|) \\
& =\|\mathrm{T} x-\mathrm{T} y\| \\
& \leqslant h \nabla\left(\left\|x_{1}-\mathrm{y}_{1}\right\|,\left\|\mathrm{x}_{2}-\mathrm{y}_{2}\right\|, \cdots,\left\|\mathrm{x}_{\mathrm{N}}-\mathrm{y}_{\mathrm{N}}\right\|\right) \\
& =h\|x-y\|_{*}
\end{aligned}
$$

for all $x=\left(x_{1}, x_{2}, \cdots, x_{N}\right), y=\left(y_{1}, y_{2}, \cdots, y_{N}\right) \in C^{N}$. Hence $T^{*}$ is a non-self contraction mapping in Banach space $\left(\mathrm{X}^{\mathrm{N}},\|\cdot\|_{*}\right)$. This completes the proof.

Lemma 3.4. Let $\mathrm{C}$ be a nonempty subset of a Banach space $(\mathrm{X},\|\cdot\|)$. Banach space $\left(\mathrm{X}^{\mathrm{N}},\|\cdot\|_{*}\right)$ is defined by Lemma 3.1. Let $\mathrm{T}: \mathrm{C}^{\mathrm{N}} \rightarrow \mathrm{X}$ be an inward $\mathrm{N}$-variables non-self mapping. Let $\mathrm{T}^{*}: \mathrm{C}^{\mathrm{N}} \rightarrow \mathrm{X}^{\mathrm{N}}$ be a mapping defined as in Lemma 3.3. Then $\mathrm{T}^{*}$ is an inward non-self mapping in Banach space $\left(\mathrm{X}^{\mathrm{N}},\|\cdot\|_{*}\right)$.

Proof. Let $\mathrm{C}^{\mathrm{N}}=\mathrm{C} \times \mathrm{C} \cdots \times \mathrm{C}$ be the Cartesian product of the set $\mathrm{C}$. For any $x=\left(x_{1}, x_{2}, \cdots, x_{N}\right) \in \mathrm{C}^{\mathrm{N}}$, the inward set of $x$ relative to $C^{N}$ is the set

$$
I_{C^{N}}(x)=\left\{x+t(y-x): y \in C^{N}, t \geqslant 0\right\} .
$$

The inward set $\mathrm{I}_{\mathrm{C}^{\mathrm{N}}}(\mathrm{x})$ is also expressed as follows

$$
\begin{aligned}
\mathrm{I}_{C^{N}}(x) & =\left\{x+t(y-x): y \in C^{N}, t \geqslant 0\right\} \\
& =\left\{\left(x_{1}, x_{2}, \cdots, x_{N}\right)+t\left(\left(y_{1}, y_{2}, \cdots, y_{N}\right)-\left(x_{1}, x_{2}, \cdots, x_{N}\right)\right): y \in C^{N}, t \geqslant 0\right\} \\
& =\left\{\left(x_{1}+t\left(y_{1}-x_{1}\right), x_{2}+t\left(y_{2}-x_{2}\right), \cdots, x_{N}+t\left(y_{N}-x_{n}\right): y \in C^{N}, t \geqslant 0\right\}\right. \\
& =I_{C}\left(x_{1}\right) \times I_{C}\left(x_{2}\right) \times \cdots \times I_{C}\left(x_{N}\right),
\end{aligned}
$$

where $y=\left(y_{1}, y_{2}, \cdots, y_{N}\right)$. Since $T$ is an inward $N$-variables non-self mapping, we have $T x \in I_{C}\left(x_{i}\right)$ for all $x=\left(x_{1}, x_{2}, \cdots, x_{N}\right) \in C^{N}$ so that $T^{*} x=(T x, T x, \cdots, T x) \in I_{C^{N}}(x)$. Then $T^{*}$ is an inward non-self mapping in Banach space $\left(\mathrm{X}^{\mathrm{N}},\|\cdot\|_{*}\right)$. This completes the proof.

It is easy to see that

$$
\overline{\mathrm{I}_{C^{N}}(x)}=\overline{\mathrm{I}_{C^{N}}\left(x_{1}\right)} \times \overline{\mathrm{I}_{C^{N}}\left(x_{2}\right)} \times \cdots \times \overline{\mathrm{I}_{C^{N}}\left(x_{N}\right)}
$$

for all $x=\left(x_{1}, x_{2}, \cdots, x_{N}\right)$. From Lemma 3.4, we can get the following conclusion.

Lemma 3.5. Let $\mathrm{C}$ be a nonempty subset of a Banach space $(X,\|\cdot\|)$. Banach space $\left(\mathrm{X}^{\mathrm{N}},\|\cdot\|_{*}\right)$ is defined by Lemma 3.1. Let $\mathrm{T}: \mathrm{C}^{\mathrm{N}} \rightarrow \mathrm{X}$ be a weakly inward $\mathrm{N}$-variables non-self mapping. Let $\mathrm{T}^{*}: \mathrm{C}^{\mathrm{N}} \rightarrow \mathrm{X}^{\mathrm{N}}$ be a mapping defined as in Lemma 3.3. Then $\mathrm{T}^{*}$ is a weakly inward non-self mapping in Banach space $\left(\mathrm{X}^{\mathrm{N}},\|\cdot\|_{*}\right)$.

The following are our main results.

Theorem 3.6. Let $\mathrm{C}$ be a nonempty closed convex subset of a Banach space $(\mathrm{X},\|\cdot\|)$. Let $\mathrm{T}: \mathrm{C}^{\mathrm{N}} \rightarrow \mathrm{X}$ be a weakly inward $\mathrm{N}$-variables non-self $\nabla$-contraction mapping. Then $\mathrm{T}$ has a unique multivariate fixed point $\mathrm{p} \in \mathrm{C}$.

Proof. Let Banach space $\left(\mathrm{X}^{\mathrm{N}},\|\cdot\|_{*}\right)$ be defined as in Lemma 3.1, and the mapping $\mathrm{T}^{*}: \mathrm{C}^{\mathrm{N}} \longrightarrow \mathrm{X}^{\mathrm{N}}$ be defined as in Lemma 3.3. It is obvious that, $C^{N}$ is a nonempty closed convex in Banach space $\left(X^{N}, \|\right.$. $\left.\|_{*}\right)$. By using Lemma 3.5, we know that $\mathrm{T}^{*}$ is a weakly inward non-self contraction in Banach space $\left(\mathrm{X}^{\mathrm{N}},\|\cdot\|_{*}\right)$. Then, by using Theorem $1.2, \mathrm{~T}^{*}$ has a unique fixed point $\mathrm{P} \in \mathrm{C}^{\mathrm{N}}$. There exists an element $\mathrm{P}=\left(\mathrm{p}_{1}, \mathrm{p}_{2}, \cdots, \mathrm{p}_{\mathrm{N}}\right) \in \mathrm{C}^{\mathrm{N}}$ such that

$$
\mathrm{T}^{*}\left(\mathrm{p}_{1}, \mathrm{p}_{2}, \cdots, \mathrm{p}_{\mathrm{N}}\right)=(\mathrm{TP}, \mathrm{TP}, \cdots, \mathrm{TP})=\left(\mathrm{p}_{1}, \mathrm{p}_{2}, \cdots, \mathrm{p}_{\mathrm{N}}\right),
$$

which implies $p_{1}=p_{2}=\cdots=p_{N}$. Let $p=p_{1}=p_{2}=\cdots=p_{N}$, then $T(p, p, \cdots, p)=p$. Hence, $T$ has a unique multivariate fixed point $p \in C$. This completes the proof. 
Let $\nabla$ be $\nabla_{2}, \nabla_{3}, \nabla_{4}$, respectively, we can get the following corollaries.

Corollary 3.7. Let $\mathrm{C}$ be a nonempty closed convex subset of a Banach space $(\mathrm{X},\|\cdot\|)$. Let $\mathrm{T}: \mathrm{C}^{\mathrm{N}} \rightarrow \mathrm{X}$ be a weakly inward $\mathrm{N}$-variables non-self mapping satisfying the following condition

$$
\|T x-T y\| \leqslant h \sum_{i=1}^{N} \lambda_{i}\left\|x_{i}-y_{i}\right\|, \quad \sum_{i=1}^{N} \lambda_{i}=1
$$

for all $x=\left(x_{1}, x_{2}, \cdots, x_{N}\right), y=\left(y_{1}, y_{2}, \cdots, y_{N}\right) \in C^{N}$, where $h, \lambda_{i} \in(0,1)$ are constants. Then $T$ has a unique multivariate fixed point $\mathrm{p} \in \mathrm{C}$.

Corollary 3.8. Let $\mathrm{C}$ be a nonempty closed convex subset of a Banach space $(\mathrm{X},\|\cdot\|)$. Let $\mathrm{T}: \mathrm{C}^{\mathrm{N}} \rightarrow \mathrm{X}$ be a weakly inward $\mathrm{N}$-variables non-self mapping satisfying the following condition

$$
\|T x-T y\| \leqslant h \sqrt{\frac{1}{N} \sum_{i=1}^{N}\left\|x_{i}-y_{i}\right\|^{2}}
$$

for all $\mathrm{x}=\left(\mathrm{x}_{1}, \mathrm{x}_{2}, \cdots, \mathrm{x}_{\mathrm{N}}\right), \mathrm{y}=\left(\mathrm{y}_{1}, \mathrm{y}_{2}, \cdots, \mathrm{y}_{\mathrm{N}}\right) \in \mathrm{C}^{\mathrm{N}}$, where $\mathrm{h} \in(0,1)$ is a constant. Then $\mathrm{T}$ has a unique multivariate fixed point $\mathrm{p} \in \mathrm{C}$.

Corollary 3.9. Let $\mathrm{C}$ be a nonempty closed convex subset of a Banach space $(\mathrm{X},\|\cdot\|)$. Let $\mathrm{T}: \mathrm{C}^{\mathrm{N}} \rightarrow \mathrm{X}$ be a weakly inward $\mathrm{N}$-variables non-self mapping satisfying the following condition

$$
\|T x-T y\| \leqslant h \max \left\{\left\|x_{1}-y_{1}\right\|,\left\|x_{2}-y_{2}\right\|, \cdots,\left\|x_{N}-y_{N}\right\|\right\}
$$

for all $\mathrm{x}=\left(\mathrm{x}_{1}, \mathrm{x}_{2}, \cdots, \mathrm{x}_{\mathrm{N}}\right), \mathrm{y}=\left(\mathrm{y}_{1}, \mathrm{y}_{2}, \cdots, \mathrm{y}_{\mathrm{N}}\right) \in \mathrm{C}^{\mathrm{N}}$, where $\mathrm{h} \in(0,1)$ is a constant. Then $\mathrm{T}$ has a unique multivariate fixed point $\mathrm{p} \in \mathrm{C}$.

Remark 3.10. Consider T is not a self-mapping, then Picard iterative algorithm can not be directly used to approximate the multivariate fixed point of T. In order to overcome this problem, in this article, we add an expansive mapping to the iterative algorithm such that the relative iterative sequence can approximate to the multivariate fixed point of $\mathrm{T}$.

Theorem 3.11 (Iterative algorithm). Let $\mathrm{C}$ be a nonempty closed convex subset of a Banach space $(\mathrm{X},\|\cdot\|)$. Let $\mathrm{T}: \mathrm{C}^{\mathrm{N}} \rightarrow \mathrm{X}$ be a weakly inward $\mathrm{N}$-variables non-self $\nabla$-contraction mapping. Assume there exists an expansive mapping $\mathrm{P}: \mathrm{C} \longrightarrow \mathrm{R}(\mathrm{T}) \subset \mathrm{X}$, where $\mathrm{R}(\mathrm{T})$ is the range of the mapping $\mathrm{T}$, then for any $\mathrm{p}_{0} \in \mathrm{C}^{\mathrm{N}}$, the iterative sequence $\left\{p_{n}\right\} \subset C^{N}$ defined by:

$$
\begin{aligned}
p_{1} & =\left(\mathrm{P}^{-1} \mathrm{~T} p_{0}, \mathrm{P}^{-1} \mathrm{~T} \mathrm{p}_{0}, \cdots, \mathrm{P}^{-1} \mathrm{~T} \mathrm{p}_{0}\right), \\
\mathrm{p}_{2} & =\left(\mathrm{P}^{-1} \mathrm{~T} \mathrm{p}_{1}, \mathrm{P}^{-1} \mathrm{~T} \mathrm{p}_{1}, \cdots, \mathrm{P}^{-1} \mathrm{~T} \mathrm{p}_{1}\right), \\
\mathrm{p}_{3} & =\left(\mathrm{P}^{-1} \mathrm{~T} \mathrm{p}_{2}, \mathrm{P}^{-1} \mathrm{~T} \mathrm{p}_{2}, \cdots, \mathrm{P}^{-1} \mathrm{~T} \mathrm{p}_{2}\right), \\
& \vdots \\
\mathrm{p}_{\mathrm{n}+1} & =\left(\mathrm{P}^{-1} \mathrm{~T} \mathrm{p}_{\mathrm{n}}, \mathrm{P}^{-1} \mathrm{~T} \mathrm{p}_{\mathrm{n}}, \cdots, \mathrm{P}^{-1} \mathrm{~T} \mathrm{p}_{\mathrm{n}}\right),
\end{aligned}
$$

converges, in the norm $\|\cdot\|_{*}$, to $(\mathrm{p}, \mathrm{p}, \cdots, \mathrm{p}) \in \mathrm{C}^{\mathrm{N}}$ and the iterative sequence $\left\{\mathrm{P}^{-1} \mathrm{~T} \mathrm{p}_{n}\right\} \subset \mathrm{X}$ converges, in the norm $\|\cdot\|$, to $\mathrm{p} \in \mathrm{C}$.

Proof. Let $A$ be a mapping defined by $A=P^{-1} T$ from $C^{N}$ into $C$, where $\mathrm{P}^{-1}$ is the inverse of the expansive 
mapping $P$. Let $A^{*}$ be a mapping defined by

$$
A^{*}(x)=(A x, A x, \cdots, A x)=\left(P^{-1} \mathrm{~T} x, P^{-1} T x, \cdots, P^{-1} T x\right)
$$

for all $x=\left(x_{1}, x_{2}, \cdots, x_{N}\right) \in C^{N}$. Then $A^{*}$ is a self-mapping from $C^{N}$ into it-self. Observe

$$
\begin{aligned}
\left\|A^{*} x-A^{*} y\right\|_{*} & =\nabla\left(\left\|\mathrm{P}^{-1} \mathrm{~T} x-\mathrm{P}^{-1} \mathrm{~T} y\right\|,\left\|\mathrm{P}^{-1} \mathrm{~T} x-\mathrm{P}^{-1} \mathrm{~T} y\right\|, \cdots,\left\|\mathrm{P}^{-1} \mathrm{~T} x-\mathrm{P}^{-1} \mathrm{~T} y\right\|\right) \\
& \leqslant \nabla(\|\mathrm{T} x-\mathrm{T} y\|,\|\mathrm{T} x-\mathrm{T} y\|, \cdots,\|\mathrm{T} x-\mathrm{T} y\|) \\
& =\|\mathrm{T} x-\mathrm{T} y\| \\
& \leqslant h \nabla\left(\left\|x_{1}-\mathrm{y}_{1}\right\|,\left\|x_{2}-\mathrm{y}_{2}\right\|, \cdots,\left\|\mathrm{x}_{\mathrm{N}}-\mathrm{y}_{\mathrm{N}}\right\|\right) \\
& =h\|x-y\|_{*}
\end{aligned}
$$

for all $x=\left(x_{1}, x_{2}, \cdots, x_{N}\right), y=\left(y_{1}, y_{2}, \cdots, y_{N}\right) \in C^{N}$. Observe, $C^{N}$ is a nonempty closed convex set in Banach space $\left(X^{N},\|\cdot\|_{*}\right)$ provided $C$ is a nonempty closed convex set in Banach space $(X,\|\cdot\|)$. By using Banach contraction mapping principle, there exists a unique element $p^{*}=\left(p_{1}, p_{2}, \cdots, p_{N}\right) \in C^{N}$ such that $A^{*} p^{*}=p^{*}$. Meanwhile, for any given initial point $p_{0} \in C^{N}$, the Picard iterative sequence $p_{n+1}=A^{*} p_{n}$ converges, in the norm $\|\cdot\|_{*}$, to the fixed point $p$. In addition, the iterative sequence can be expressed as follows

$$
\begin{aligned}
p_{1} & =\left(\mathrm{P}^{-1} \mathrm{~T} \mathrm{p}_{0}, \mathrm{P}^{-1} \mathrm{~T} \mathrm{p}_{0}, \cdots, \mathrm{P}^{-1} \mathrm{~T} \mathrm{p}_{0}\right), \\
\mathrm{p}_{2} & =\left(\mathrm{P}^{-1} \mathrm{~T} \mathrm{p}_{1}, \mathrm{P}^{-1} \mathrm{~T} \mathrm{p}_{1}, \cdots, \mathrm{P}^{-1} \mathrm{~T} \mathrm{p}_{1}\right), \\
\mathrm{p}_{3} & =\left(\mathrm{P}^{-1} \mathrm{~T} \mathrm{p}_{2}, \mathrm{P}^{-1} \mathrm{~T} \mathrm{p}_{2}, \cdots, \mathrm{P}^{-1} \mathrm{~T} \mathrm{p}_{2}\right), \\
& \vdots \\
\mathrm{p}_{\mathrm{n}+1} & =\left(\mathrm{P}^{-1} \mathrm{~T} \mathrm{p}_{\mathrm{n}}, \mathrm{P}^{-1} \mathrm{~T} \mathrm{p}_{\mathrm{n}}, \cdots, \mathrm{P}^{-1} \mathrm{~T} \mathrm{p}_{\mathrm{n}}\right),
\end{aligned}
$$

From the above expression, we also know that $p_{1}=p_{2}=\cdots=p_{N}$. Let $p_{i}=p, i=1,2, \cdots, N$, then $p^{*}=(p, p, \cdots, p)$. Then the iterative sequence $\left\{p_{n}\right\}$ converges, in the norm $\|\cdot\|_{*}$, to $(p, p, \cdots, p) \in C^{N}$ and the iterative sequence $\left\{\mathrm{P}^{-1} \mathrm{~T} \mathrm{p}_{n}\right\} \subset \mathrm{X}$ converges, in the norm $\|\cdot\|$, to $\mathrm{p} \in \mathrm{C}$. This completes the proof.

Let $\mathrm{C}$ be a nonempty closed convex subset of a Hilbert space $\mathrm{X}$. Let $\mathrm{P}_{\mathrm{C}}$ denote the metric projection from $X$ onto $C$, then $\left(\mathrm{P}_{\mathrm{C}}\right)^{-1}: \mathrm{C} \rightarrow \mathrm{X}$ is an expansive mapping. By using Theorem 3.11, we can get the following conclusion.

Corollary 3.12 (Iterative algorithm). Let $\mathrm{C}$ be a nonempty closed convex subset of a Hilbert space $(\mathrm{X},\|\cdot\|)$. Let $\mathrm{T}: \mathrm{C}^{\mathrm{N}} \rightarrow \mathrm{X}$ be a weakly inward $\mathrm{N}$-variables non-self $\nabla$-contraction mapping. Then for any $\mathrm{p}_{0} \in \mathrm{C}^{\mathrm{N}}$, the iterative sequence $\left\{\mathrm{p}_{\mathrm{n}}\right\} \subset \mathrm{C}^{\mathrm{N}}$ defined by:

$$
\begin{aligned}
p_{1} & =\left(P_{C} T p_{0}, P_{C} T p_{0}, \cdots, P_{C} T p_{0}\right), \\
p_{2} & =\left(P_{C} T p_{1}, P_{C} T p_{1}, \cdots, P_{C} T p_{1}\right), \\
p_{3} & =\left(P_{C} T p_{2}, P_{C} T p_{2}, \cdots, P_{C} T p_{2}\right), \\
& \vdots \\
p_{n+1} & =\left(P_{C} T p_{n}, P_{C} T p_{n}, \cdots, P_{C} T p_{n}\right),
\end{aligned}
$$

converges, in the norm $\|\cdot\|_{*}$, to $(p, p, \cdots, p) \in C^{N}$ and the iterative sequence $\left\{P_{C} T p_{n}\right\} \subset X$ converges, in the norm $\|\cdot\|$, to $\mathrm{p} \in \mathrm{C}$, where $\mathrm{P}_{\mathrm{C}}$ denotes the metric projection from $\mathrm{X}$ onto $\mathrm{C}$.

Example 3.13. Let $X=(-\infty,+\infty), C=[0,+\infty)$. Let $T: C^{2} \rightarrow X$ be a 2-variables non-self contraction mapping defined by

$$
\mathrm{T}\left(\mathrm{x}_{1}, \mathrm{x}_{2}\right)=-\frac{\mathrm{x}_{1}}{2}, \quad \forall\left(\mathrm{x}_{1}, \mathrm{x}_{2}\right) \in \mathrm{C}^{2} .
$$


Note the fact that

$$
\begin{aligned}
\left\|T\left(x_{1}, x_{2}\right)-T\left(y_{1}, y_{2}\right)\right\| & =\frac{1}{2}\left\|x_{1}-y_{1}\right\| \\
& \leqslant \frac{1}{2} \sqrt{\left(x_{1}-y_{1}\right)^{2}+\left(x_{2}-y_{2}\right)^{2}} \\
& =\frac{1}{\sqrt{2}} \sqrt{\frac{1}{2}\left(\left(x_{1}-y_{1}\right)^{2}+\left(x_{2}-y_{2}\right)^{2}\right)} \\
& =\frac{1}{\sqrt{2}} \Delta_{3}\left(\left\|x_{1}-y_{1}\right\|,\left\|x_{2}-y_{2}\right\|\right)
\end{aligned}
$$

for all $\left(x_{1}, x_{2}\right),\left(y_{1}, y_{2}\right) \in C^{2}$. The $p=0$ is a unique multivariate fixed point of $T$, that is $T(0,0)=0$. For any given $p_{0}=\left(p_{0,1}, p_{0,2}\right) \in C^{2}$, the iterative sequence $\left\{p_{n}\right\} \subset C^{2}$ defined by:

$$
\begin{aligned}
p_{1} & =\left(P^{-1} T p_{0}, P^{-1} T p_{0}\right)=\left(-T p_{0},-T p_{0}\right)=\left(\frac{1}{2} p_{0,1}, \frac{1}{2} p_{0,1}\right), \\
p_{2} & =\left(P^{-1} T p_{1}, P^{-1} T p_{1}\right)=\left(-T p_{1},-T p_{1}\right)=\left(\frac{1}{4} p_{0,1}, \frac{1}{4} p_{0,1}\right), \\
p_{3} & =\left(P^{-1} T p_{2}, P^{-1} T p_{2}\right)=\left(-T p_{2},-T p_{2}\right)=\left(\frac{1}{8} p_{0,1}, \frac{1}{8} p_{0,1}\right), \\
& \vdots \\
p_{n+1} & =\left(P^{-1} T p_{n}, P^{-1} T p_{n}\right)=\left(-T p_{n},-T p_{n}\right)=\left(\frac{1}{2^{n+1}} p_{0,1}, \frac{1}{2^{n+1}} p_{0,1}\right),
\end{aligned}
$$

converges to $(0,0)$ and $\mathrm{P}^{-1} \mathrm{~T} \mathrm{p}_{\mathrm{n}}=\frac{1}{2^{\mathrm{n}+1}} \mathrm{p}_{0,1}$ converges to 0 , where $\mathrm{P}: \mathrm{C} \longrightarrow \mathrm{X}$ is an expansive mapping defined by $P x=-x$.

In Example 3.13, we see, for any $\left(x_{1}, x_{2}\right) \in C^{2}$, that, if $x_{1}, x_{2}>0$, then $I_{C}\left(x_{1}\right)=I_{C}\left(x_{2}\right)=X$, hence $\mathrm{T}\left(x_{1}, x_{2}\right) \in \mathrm{I}_{C}\left(x_{i}\right), i=1,2$, if $x_{1}=0$, then $\mathrm{T}\left(x_{1}, x_{2}\right)=0 \in \mathrm{I}_{C}\left(x_{i}\right), i=1,2$, if $x_{1}>0, x_{2}=0$, then $\mathrm{I}_{\mathrm{C}}\left(\mathrm{x}_{1}\right)=\mathrm{X}, \mathrm{I}_{\mathrm{C}}\left(\mathrm{x}_{2}\right)=\mathrm{C}$, hence $\mathrm{T}\left(\mathrm{x}_{1}, \mathrm{x}_{2}\right)=-\frac{1}{2} \mathrm{x}_{1} \notin \mathrm{I}_{\mathrm{C}}\left(\mathrm{x}_{2}\right)$. Therefore $\mathrm{T}$ is not weakly inward. We have naturally the following open question.

\section{Open question}

Let $C$ be a nonempty closed convex subset of a Banach space $(X,\|\cdot\|)$. Let $T: C^{N} \rightarrow X$ be an $N$ variables non-self $\nabla$-contraction mapping. What conditions guarantee that $T$ has a unique multivariate fixed point $p \in C$ ?

\section{Acknowledgment}

This project is supported by the major project of Hebei North University under grant No. ZD201304.

\section{References}

[1] R. Agarwal, D. Regan, D. Rahu, Fixed point theory for Lipschitzian-type mappings with applications, Springer, New York, (2009). 1, 1.2, 2.2, 2.3, 2.4

[2] A. Amini-Harandi, H. Emami, A fixed point theorem for contraction type maps in partially ordered metric spaces and application to ordinary differential equations, Nonlinear Anal., 72 (2010), 2238-2242. 1

[3] D. W. Boyd, J. S. W. Wong, On nonlinear contractions, Proc. Amer. Math. Soc., 20 (1969), 458-464.

[4] F. E. Browder, On the convergence of successive approximations for nonlinear functional equations, Nederl. Akad. Wetensch. Proc. Ser. A 71, Indag. Math., 30 (1968), 27-35. 1 
[5] J. Caristi, Fixed point theorem for mappings satisfying inwardness conditions, Tran. Amer. Math. Soc., 215 (1976), $241-$ 251. 1

[6] M. A. Geraghty, On contractive mappings, Proc. Am. Math. Soc., 40 (1973), 604-608. 1, 1.1

[7] T. Gnana Bhaskar, V. Lakshmikantham, Fixed point theorems in partially ordered metric spaces and applications, Nonlinear Anal., 65 (2006), 1379-1393. 1

[8] J. Harjani, K. Sadarangni, Fixed point theorems for weakly contraction mappings in partially ordered sets, Nonlinear Anal., 71 (2009), 3403-3410. 1

[9] J. Harjani, K. Sadarangni, Generalized contractions in partially ordered metric spaces and applications to ordinary differential equations, Nonlinear Anal., 72 (2010), 1188-1197.

[10] J. R. Jachymski, Equivalence of some contractivity properties over metrical structures, Proc. Amer. Math. Soc., 125 (1997), 2327-2335. 1

[11] J. Jachymski, I. Jóźwik, Nonlinear contractive conditions: a comparison and related problems, in: Fixed Point Theory and its Applications, Banach Center Publisher, 77 (2007), 123-146. 1

[12] M. S. Khan, M. Swaleh, S. Sessa, Fixed point theorems by altering distances between the points, Bull. Aust. Math. Soc., 30 (1984), 1-9. 1

[13] V. Lakshmikantham, L. Ciric, Coupled fixed point theorems for nonlinear contractions in partially ordered metric spaces, Nonlinear Anal., 70 (2009), 4341-4349.

[14] J. Nieto, R. Rodriguez-López, Contractive mapping theorems in partially ordered sets and applications to ordinary differential equations, Order, 22 (2005), 223-239. 1

[15] J. J. Nieto, R. Rodriguez-López, Existence and uniqueness of fixed point in partially ordered sets and applications to ordinary differential equations, Acta Math. Sin., 23 (2007), 2205-2212. 1

[16] B. Samet, C. Vetro, P. Vetro, Fixed point theorem for $\alpha-\psi$-contractive type mappings, Nonlinear Anal., 75 (2012), 21542165.

[17] Y. Su, A. Petruşel, J. Yao, Multivariate fixed point theorems for contractions and nonexpansive mappings with applications, Fixed Point Theory and Appl., 2016 (2016), 19 pages. 1, 2.1

[18] Y. Su, J.-C. Yao, Further generalized contraction mapping principle and best proximity theorem in metric spaces, Fixed Point Theory and Appl., 2015 (2015), 13 pages. 1

[19] F. Yan Y. Su, Q. Feng, A new contraction mapping principle in partially ordered metric spaces and applications to ordinary differential equations, Fixed Point Theory Appl., 2012 (2012), 13 pages. 1 